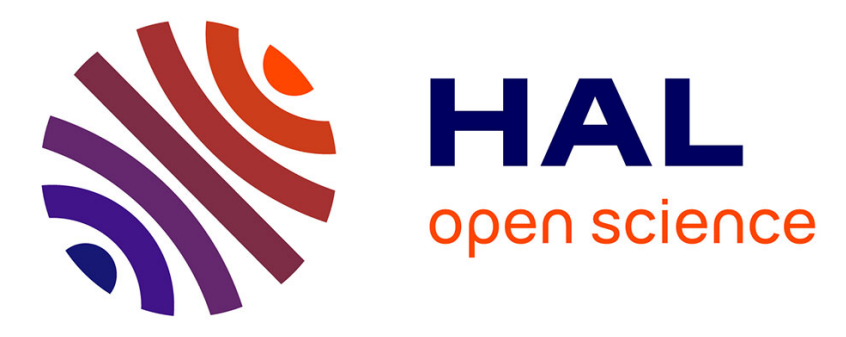

\title{
Study of Slag Blended Cement and the Influence of Triethanolamine
}

Rachel Reiver, Nathalie Azéma, Gwenn Le Saout, Lucia Ferrari, Vanessa

Kocaba

\section{- To cite this version:}

Rachel Reiver, Nathalie Azéma, Gwenn Le Saout, Lucia Ferrari, Vanessa Kocaba. Study of Slag Blended Cement and the Influence of Triethanolamine. ICCM 2021 - 11th ACI/RILEM International Conference on Cementitious Materials and Alternative Binders for Sustainable Concrete, Jun 2021, En ligne, Canada. hal-03268522

\section{HAL Id: hal-03268522 https://hal.science/hal-03268522}

Submitted on 23 Jun 2021

HAL is a multi-disciplinary open access archive for the deposit and dissemination of scientific research documents, whether they are published or not. The documents may come from teaching and research institutions in France or abroad, or from public or private research centers.
L'archive ouverte pluridisciplinaire HAL, est destinée au dépôt et à la diffusion de documents scientifiques de niveau recherche, publiés ou non, émanant des établissements d'enseignement et de recherche français ou étrangers, des laboratoires publics ou privés. 


\title{
Study of Slag Blended Cement and the Influence of Triethanolamine
}

\author{
Rachel Reiver1,2, ${ }^{*}$ N. Azéma1, G. Le Saoût1, L. Ferrari2, V. Kocaba2 \\ 1 University of Montpellier - IMT Mines Alès, Centre des Matériaux, 6 avenue \\ de Clavières, 30319 Alès cedex, France
}

2 CHRYSO, 7 rue de l'Europe, 45300 Sermaises France

Synopsis: Ordinary Portland cement (OPC) production contributes significantly to greenhouse gas emissions. Substituting a part of clinker by supplementary cementitious materials as slag allows reducing this impact. However, these materials have a slower hydration kinetics, which makes a mechanical, thermal or chemical activation necessary. Triethanolamine (TEA) is an amine commonly used as an accelerator, as it allows activating chemically the hydration. The mechanisms involved in this activation still need to be further investigated. Therefore, this study focuses on the interaction of TEA with slag blended cement. The slag blended cement paste was firstly studied without accelerator to highlight the impact of this mineral addition on the OPC reactivity. The effect of TEA on chemical reactivity was investigated by isothermal calorimetric measurements and scanning electron microscopy. The effects on the structural organization of the paste were highlighted by comparing particles size distributions and physicochemical stabilities of slightly diluted pastes. By combining the analysis of paste dispersion state and chemical reactivity, this study allowed identifying different modes of action of triethanolamine in slag blended cement in comparison with an OPC and a limestone blended cement used as references. 
Keywords: Blast-furnace slag, acceleration, cement hydration, particle size

\section{INTRODUCTION}

Blast furnace slag is a co-product of the cast iron production and is used as a supplementary cementitious material (SCM) in cement industry. The decrease of the amount of clinker allows reducing the $\mathrm{CO}_{2}$ footprint, the cost and the heat of hydration at early age of hydration of Ordinary Portland Cement (OPC). Thanks to its amorphous structure and its chemical composition close to that of Portland cement, slag has latent hydraulic properties. Therefore, slag reacts with water to produce hydrates like cement but much more slowly and needs to be activated. This activation has to be performed at high $\mathrm{pH}$ and can be done in a chemical or thermal process. Many researchers $\left({ }^{1,2}\right)$ have studied the impact of slag on Portland cement highlighting its chemical and physicochemical contributions on the cement hydration.

Slag is not reactive during the first hours of hydration, but its filler effect increases the cement reactivity and its hydraulic binder reactivity (generally observed from 2 days on the heat flow) and improves the strengths at middle term (from seven days). However, compared to an OPC, due to the dilution effect of the clinker, it reduces the heat release and the mechanical properties. In order to improve mechanical properties at early age, admixtures as accelerator systems (also called activators or quality improvers) are often added to blended cement. Triethanolamine (TEA) is one of the main molecules used as cement chemical admixture thanks to its various functions as grinding aid for cement manufacturing and its accelerating function, to regulate the setting time and to improve strength. Chemically, TEA slows down calcium silicate hydration, improves calcium aluminate hydration and extends the induction period $\left(^{3-6}\right)$. Regarding the mesostructural organization in the cement paste, TEA seems to disperse cement particles, allowing a better stabilization of the paste during the setting of cement $\left({ }^{7}\right)$.

Only a few studies investigated the mode of action of cement chemical admixtures by evaluating their combined effects on the mesostructural organization of cement pastes $\left({ }^{8,9}\right)$ and their chemical impact. The mesostructural organization corresponds to the granular arrangement of particles in a suspension (a cement paste with a water to cement ratio (W/C) of 0.4 can be considered as a very concentrated suspension $\left({ }^{10}\right)$ with a scale going from nanometric to macroscopic dimensions. Mineral additives can also impact this organization by modifying and bringing heterogeneity of chemical nature, size, shape, surface and density of particles factors driving stability and reactivity of cement paste.

Therefore, the aim of this study is to investigate the impact of TEA on the chemical reactivity and mesostructural organization of slag blended cement paste in order to understand its mode of action on cement hydration and stability, including the impact of slag in the system. In this work, most experiments have been performed at early age (first hours of hydration) in order to compare the observations obtained on the mesostructural organization of the paste and on the reactivity.

\section{MATERIALS AND METHODS}




\section{Materials}

As raw materials, a clinker, a calcium sulfate, a blast furnace slag and a limestone were used. The clinker and the calcium sulfate were ground in a ball mill and then mixed, with the respective proportions $95 \mathrm{wt} . \%$ and $5 \mathrm{wt} . \%$, to obtain an OPC free of grinding aids. The slag and limestone blended cements (labelled respectively OPC-S and OPC-L) were prepared by mixing $40 \mathrm{wt} . \%$ of the materials with the OPC. All mixes were performed using a TURBULA shaker-mixer for 1 hour to ensure a good initial homogenization of the powder. Chemical, mineralogical and granular characteristics of the raw materials are given in Table 1. The accelerator molecule studied, TEA, has an active material content of $80 \mathrm{wt} . \%$ determined by gas chromatography.

\section{Methods}

\section{Granular characterizations}

The granular characterization of the raw materials (powders and pastes) was investigated by studying shapes, sizes and surface areas of the particles.

The surface areas of the powders were obtained from two technics: the BET (BrunauerEmmett-Teller) specific surface and the Blaine specific surface. For the first one, the BET specific surface, the measurements were performed with the TriStar II PLUS device of Micromeritics under nitrogen flow. The powder is degassed during 24 hours before analysis. Then, the BET surface area is obtained with the amount of nitrogen absorbed on the particle surface in function of the pressure applied with the theory of Brunauer, Emmett and Teller. For the second one, the Blaine specific measurement was made according to the cement standard [NF EN 196-6]. The fineness of the powder is related to the time taken by a volume of air to pass through a bed of the compacted powder.

The particles size distribution (PSD) was analyzed with a Beckman Coulter LS 13320 laser granulometer. The measurements were based on a static light scattering of monochromatic light $(750 \mathrm{~nm}[0.030 \mathrm{mil}])$ deviated by particles in suspension. The scattering is directly correlated to the particle diameter thanks to refractive indexes constituted of a real and an imaginary part specific of each material. The real part was calculated from XRD data (and XRF data when amorphous phase is present) by a weighted average of the mineral phases refractive index given in the literature $\left(\left({ }^{1,11-16}\right)\right.$. The imaginary part was fixed to $0.1\left({ }^{1,17}\right)$. The Table 2 lists the refractive index calculated and used for each material. The measurements were performed in isopropanol (dispersant middle widely used in scientific literature) or in a synthetic interstitial liquid diluted (thereby simulating real paste environment) and lasted for $90 \mathrm{~s}$. About $1 \mathrm{~g}$ [0.0022 $\mathrm{lb}$ ] of powder or paste is diluted in $100 \mathrm{~mL}$ [0.026 gal] of the liquid used as analytical environment. The suspension is gently mixed for 10 minutes before introducing few drops into the device where the suspension is agitated with a pump power of $40 \%$. The results gave the variation of volume percentage as a function of particle diameter with the main mode and size spreading (difference between the maximal and the minimal diameter).

The particle morphology was observed with a FEIQUANTA 200 FEG environmental scanning electron microscopy (SEM) using secondary electron (SE) mode. 


\section{Cement paste preparation}

The cement pastes were prepared with a W/B ratio of 0.4 and different dosages in TEA from 0.01 wt. $\%$ to $0.3 \mathrm{wt} . \%$ of dry mass extract with respect to cement. In practice, the maximal dosage of an amine is around $0.25 \mathrm{wt} . \%$ but in this work higher dosages were also studied to exacerbate the action of TEA $\left({ }^{7,18}\right)$. The mixing protocol, performed using a radial flow impeller blade fixed to a Stuart SS30 mixer, was to stir the mix at $52.4 \mathrm{rad} / \mathrm{s}$ [500 rpm] during the first minute, then stop for $1 \mathrm{~min}$ to scrape the blade and beaker and finally to stir at $104.7 \mathrm{rad} / \mathrm{s}$ [1000 rpm] for a minute. The pastes made from only OPC were called OPC and those from limestone and slag blended cement, OPC-L and OPC-S.

The pastes of slag and limestone independently (labelled S and L) were also made by mixing with a synthetic interstitial liquid whose composition was adapted from the pore solution of a CEM I $42.5 \mathrm{~N}$ paste $(\mathrm{W} / \mathrm{C}=0.5){ }^{19}$ after $1 \mathrm{~h}$ of hydration: gypsum $\left(\mathrm{CaSO}_{4}, 2 \mathrm{H}_{2} \mathrm{O}\right)=0.8 \mathrm{~g} / \mathrm{L}$ $[0.11 \mathrm{oz} / \mathrm{gal}]$, potassium sulfate $\left(\mathrm{K}_{2} \mathrm{SO}_{4}\right)=19.4 \mathrm{~g} / \mathrm{L}$ [2.6 oz/gal], sodium hydroxide $(\mathrm{NaOH})$ $=0.9 \mathrm{~g} / \mathrm{L}[0.12 \mathrm{oz} / \mathrm{gal}]$ and potassium hydroxide $(\mathrm{KOH})=4.3 \mathrm{~g} / \mathrm{L}[0.57 \mathrm{oz} / \mathrm{gal}]$. Experimentally, lower ion concentrations were used to avoid some precipitation of portlandite.

\section{Physicochemical stability}

A concentrated dispersion analyzer, Turbiscan MA 2000 (Formulaction), was used to study the settling of cement pastes. For the measurement, a monochromatic light source $(850 \mathrm{~nm}[0.0335$ mil]) scans the analysis tube containing the cement paste every 2 minutes. Transmitted and backscattered light are detected respectively at angles of $3.14 \mathrm{rad}\left[180^{\circ}\right]$ and $0.79 \mathrm{rad}\left[45^{\circ}\right]$ from incident radiation. The settling velocity and the sediment height were determined at 35 minutes. A change of transmitted ( $\mathrm{Tr}$ ) or backscattered (Bs) profiles corresponds to a modification of solid volume fraction $(\phi)$ due to particles migration and/or mean diameter value (d) due to dispersion/agglomeration phenomena and/or reactivity, ${ }^{20}$ :

$$
\operatorname{Tr}=\mathrm{e}^{\frac{-\mathrm{r}_{\mathrm{i}}}{\lambda}} \text { and } \mathrm{Bs}^{2}=\frac{(1-\mathrm{g})}{\lambda}
$$

$$
\text { With } \lambda(\phi, d)=\frac{2 d}{3 \phi Q s}
$$

$\operatorname{Tr}$ and Bs are respectively the transmitted and backscattered intensities (\%), $\mathrm{r}_{\mathrm{i}}$ the internal radius of the measuring cell $(\mu \mathrm{m}), \lambda$ the photon mean path length $(\mu \mathrm{m}), \mathrm{d}$ the average particles diameter $(\mu \mathrm{m})$ and $\phi$ the particles volume fraction. Qs and $g$ are two parameters from the Lorentz-Mie theory, respectively the scattering efficiency factor and the asymmetry factor $\left({ }^{20}\right)$.

In order to observe destabilization phenomena in a reasonable time, the pastes $(\mathrm{W} / \mathrm{B}=0.4)$ were diluted to reach a constant volume fraction of 15 vol.\% which corresponds to the W/B ratios of Table 3. After adding dilution water to cement paste, the suspension is gently mixed using a radial flow impeller blade fixed to a Stuart SS30 mixer at $20.9 \mathrm{rad} / \mathrm{s}$ [200 rpm] for $10 \mathrm{~min}$ to 
ensure a homogenous suspension. The representative error was calculated from three measurements.

\section{Hydration kinetics}

The hydration kinetics study was carried out on paste samples OPC and OPC-S systems. Additionally, the samples of OPC blended with respectively $40 \mathrm{wt} . \%$ of limestone (labelled OPC-L) were prepared as reference in order to investigate the filler effect, although limestone is known to have an slight influence on the phase assemblage $\left({ }^{21}\right)$. An isothermal calorimeter (TA Instruments TAM Air) operating at $25^{\circ} \mathrm{C}\left[77^{\circ} \mathrm{F}\right]$ was used to monitor the heat flow of cement pastes during hydration. For ex-situ measurements, the sample was introduced in the device at $5 \mathrm{~min}$ of hydration. For in-situ measurements, the sample powder was beforehand introduced and then the water was added at the beginning of the measurement with 45 seconds of mixing.

\section{RESULTS AND DISCUSSION}

\section{Granular characterizations of the raw materials}

The granular characterization was investigated by comparing the quantitative data of the particle size distributions (PSD) (Figure 1) and the granular and physical characteristics (Table 4) of the different raw materials with the observations of the size, the shape and the surface morphology obtained by SEM microscopy (Figure 2). The first one allows determining that all the particles belong to submicronic dimension (from $0.05 \mu \mathrm{m}$ [0.002 mil] to $100 \mu \mathrm{m}$ [3.9 mil]). A common main mode value around $10 \mu \mathrm{m}$ is also observed for all materials (Figure 1 and Table 4). According to the SEM micrographs (Figure 2 a-d), clinker, calcium sulfate, slag and limestone powders have a similar morphology (angular monomorphic shape and more or less finest particles agglomerated on surface of largest particles). The combination of these characteristics with the density values in Table 1 seems to satisfy the main condition required for a homogenous powder system according to ${ }^{22}$ (similar density, size and shape) and let think that the formulated blended cements (OPC, OPC-L and OPC-S) will mix easily. Thanks to these methods, the morphology and the size of the material have been sketched in Figure 2 according to the particle size defined in Figure 1.

Note that Blaine and BET specific surface values of materials have followed similar trends except for calcium sulfate values which present a low Blaine specific surface but a high BET specific surface. This means that there are a lot of fine particles identified by BET specific surface (Table 1) but not identified by laser granulometry in isopropanol (Figure 1) and Blaine specific surface measurement. The hygroscopic character of the material $\left({ }^{23}\right)$ could probably explain this last value. Note that calcium sulfate is in small amount in pastes and finest particles are quickly dissolved. 


\section{Impacts of slag}

To highlight the impact of slag on slag-blended cement, the OPC-S system was studied and characterized under different technics and compared to OPC and OPC-L systems. Comparison with OPC system allows showing the effect of slag on the clinker hydration and comparison with OPC-L system allows to differentiate the filler effect and the reactivity of the slag.

About the stability measurements, all systems studied present a hindered settling regime. It means that for all pastes the settling appears with a sharp front of settling represented by vertical lines in the transmitted signal (Figure 3). The structure of the sediment is also homogenous as shown in Figure 3 by a backscattering signal (Bs) constant over the full height of the sediment (Figure 4). Thanks to the Equation 3, it is possible to note that there is no phenomenon of size segregation. This suggests that in case of undiluted pastes, the cement paste will stay homogenous despite the bleeding.

The addition of SCM, whose particle size distributions are close to that of OPC, does not seem to affect the settling profile evolution which correspond to a hindered settling regime for all systems, with a sharp sediment front leaving a supernatant rather clear (slightly turbid) as illustrated in Figure 4. However, it had been identified that addition of SCM could impact the settling under two parameters: relative height of sediment at $35 \mathrm{~min}$ and settling velocity. The settling velocity corresponds to the first slope of the relative height variation versus time at the beginning of the settling. As shown in Figure 4, the sediment height at $35 \mathrm{~min}$ is not the same for all pastes. Figure 5 gives these variations with hydration time of relative heights for each system. It highlights that the substitution of $40 \mathrm{wt} . \%$ of OPC by slag or limestone decreases settling velocity increasing the relative height of sediment, thus the ability of compaction at early age. As seen previously, the density of the different powders are very closed (Table 1) so it should not be the main factor that impact this result unlike the nature and the size of the particles. The more the SCM contains finer particles and the main mode of particle size distribution is close to that OPC (Table 4), the more this phenomenon is pronounced.

Note that the higher values of mean $\% \mathrm{BS}$ of SCM sediment (64.3\% and $72.3 \%)$ given in Figure 4 , probably mainly due to lower mean size and lighter color of these materials compared to OPC, increase the value of $\% \mathrm{BS}$ of OPC sediment $(36.2 \%$ and $34.5 \%)$ when this one is substituted by SCM.

These results are confirmed by a study of the granular state of these system (Figure 6) in synthetic interstitial liquid (as for settling experiments) in which slag and limestone still present finer particles (below their main mode, respectively $7.1 \mu \mathrm{m}[0.28 \mathrm{mil}]$ and $8.5 \mu \mathrm{m}[0.33 \mathrm{mil}]$ ). Moreover, an agglomeration phenomenon of these finest particles of SCMs is visible when they are mixed with OPC. The agglomerate formation may contribute to expand sediment as observed in Figure 5.

Considering the chemical reactivity of OPC, the mechanisms involve a decrease of settling kinetics by the formation of hydrates creating an arrangement between the particles due to the setting. However, the OPC-L and OPC-S systems are less reactive than the OPC, the amount of clinker being lower and the SCMs are considered as nonreactive within that period. They should have a better kinetics of settling than the OPC but they do not. So, the addition of slag and limestone seems to stabilize the sediment (and maybe reduce the bleeding for a non-diluted paste) by a physicochemical and granular synergic effect with the OPC. 
To confirm this conclusion, the reactivity at very early age has been studied by in-situ calorimetry (Figure 7). In the graph normalized by weight of binder (Figure 7-a) a paste of only limestone which is non-reactive was analyzed to identify the impact of the sample preparation on the heat flow and to deduce the part due to the reactivity of the systems studied. This part, probably due to the addition of water and the energy released by the mixing, is very low compared to the reactive system and allows studying the reactivity. The Figure 7-a confirms that during the first 30 minutes of hydration, the blended systems release a heat flow lower than the OPC and so are less reactive. It confirms the physicochemical and granular impact between the SCMs and the OPC on the settling behaviors.

About reactivity and impact of slag, the filler effect was investigated by comparison of the heat flow of OPC-S and OPC-L as the limestone is a non-reactive reference. Usually, in OPC, two peaks may be observed after the initial peak of hydration which takes place immediately after the contact of cement with water (peak of dissolution in Figure 7). The first peak corresponds to the hydration reaction of the silicate phases (mainly $\mathrm{C}_{3} \mathrm{~S}$ ) and the second one is characteristic of the sulfates depletion and hydration reactions of the aluminate phases $\left({ }^{24}\right)$.

In our case (Figure 8-a), the second peak is not clearly observed due to the high amount of $\mathrm{C}_{3} \mathrm{~S}$ in the clinker and the high fineness of the powder which induces a higher reactivity. The second peak is probably overlapped with the main peak of $\mathrm{C}_{3} \mathrm{~S}$ hydration. Nevertheless, in the presence of slag, the intensity of this peak is enhanced, and the heat flow profiles are modified. In the OPC-L heat flow, the induction period is reduced, and the intensity of the main peak is higher. The increase of intensity of the main peak can be due to the filler effect caused by the fineness of the material which explains why this higher peak is also present for the OPC-S but not as much as OPC-L because the slag is not as fine as the limestone (see Table 1 and Figure 2). According to ${ }^{1}$, the reduction of the induction period may be explained by the fineness of the limestone and its reactivity during the induction period. In the case of limestone blended cements, a little amount of limestone can dissolve leading to the supersaturation of $\mathrm{Ca}(\mathrm{OH})_{2}$ in the interstitial liquid and a shorter induction period $\left({ }^{25}\right)$.

In the OPC-S heat flow the addition of slag seems to cause also a filler effect because the intensities are higher than in OPC but lower than in OPC-L because of the difference of fine particles in the two materials. However, after 15 hours of hydration the cumulated heat produced by OPC-S becomes equal and then higher than OPC-L (Figure 8-b). It is caused by the chemical impact of slag at the beginning of the hydration as already identified by ${ }^{26}$.

\section{Effects of TEA}

The TEA effect on the mesostrucural organization (Figure 9 and Figure 10) seems to reinforce the phenomenon observed Figure 5 by the OPC substitution by SCM. In Figure 9, there is an increase of sediment height at $35 \mathrm{~min}$ combined to a decrease of settling velocity, with the amount of TEA for the OPC and OPC-S more diluted pastes, with a stronger impact on the OPC which is the most reactive cement system. No change is observed for pure slag pastes even at high dosages in TEA. The presence of TEA apparently decreased the ability of compaction of the reactive systems. This result seems to confirm that the effect caused by the TEA is related to the reactivity and its impact on it. As supposed previously, the clinker consumes water and produces hydrates creating fine particles and consuming cement grains to form a network unable to pack as well as a non-reactive powder. In the presence of TEA, the 
$\mathrm{C}_{3} \mathrm{~A}$ hydration is accelerated. It forms more ettringite and improves the blocking effect of the cement reactivity on the settling. However ${ }^{7}$ identified that TEA acted in solution with a dispersant effect. Therefore, these results could be explained by a combined effect of these two phenomena, reinforced by OPC substitution by SCM.

The effects of TEA were studied on OPC and OPC-S systems (Figure 11). On the heat flow profiles, at low dosages, TEA has only a weak impact on the second peak, characteristic of aluminate hydration, which appears earlier without impact on the calcium silicate peak. It is not visible on the OPC system because both peaks overlap but the increase in intensity of the main peak suggests this phenomenon. However, at higher dosages on both systems, the induction period is extended and the main peak is delayed with a loss in intensity. Regarding the cumulative heat at 24 hours, the OPC and the OPC-S systems seem to have an optimal dosage, of respectively $0.03 \mathrm{wt} . \%$ and $0.06 \mathrm{wt} \%$ in TEA. After these optimum dosages, the induction period is noticeably increased. Depending on the dosage of TEA, the molecule can act as an accelerator at low dosage increasing $\mathrm{C}_{3} \mathrm{~A}$ hydration and as a retarder delaying $\mathrm{C}_{3} \mathrm{~S}$ hydration. According to ${ }^{5}$, the TEA improves the $\mathrm{C}_{3} \mathrm{~A}$ hydration by its adsorption on ettringite, enhancing its precipitation. Above this dosage, it is supposed that too many TEA molecules are available. This helps to produce so much ettringite that it impedes calcium silicate reactivity. It could explain the hydration delay caused by high TEA dosages and the observed delay of the calcium silicate peak.

\section{CONCLUSION}

The impact of slag on the hydration of OPC with and without TEA, molecule commonly used as an accelerator to improve the strength of blended systems, was investigated with a focus on the chemical reactivity and the physicochemical stability.

The slag particles are similar to those of the clinker. The mix is then homogenous and seems stable in suspension. However, the addition of this SCM impacts the cement physicochemical stability. On slightly diluted pastes, it decreases the settling velocity and increases the sediment height.at $35 \mathrm{~min}$. This effect on the cement compaction seems due to the agglomeration of slag and clinker fine particles in aqueous environment also caused by cement hydration. As results are similar with limestone, it can be considered that the slag acts as an inert filler during this period. The reactivity of slag appears later, visible around 15 hours on the heat flow but it needs to be confirmed by studying the microstructure of this cement paste at early age.

The TEA affects less the physicochemical stability of OPC-S than OPC during the first minutes of hydration. When more TEA is added to the system, it settles less (decrease of the settling velocity and increase of the sediment height) which is maybe caused by the formation of hydrates. TEA has no impact on slag paste settling, so it can be deduced that its impact on OPC and OPC-S is due to its effect on cement reactivity. Chemically, it was highlighted at several hours of hydration that TEA features a critical dosage below which it acts as an accelerator on aluminate phase hydration and above which it acts as a retarder increasing the induction period. Before this optimum, TEA seems to only increase calcium aluminate hydration showed by an increase in intensity of the characteristic peak and does not seem to impact the calcium silicate reactivity.

\section{ACKNOWLEDGEMENTS}


The authors thank the CIFRE convention of the French ANRT (Association Nationale de la Recherche et de la Technologie) and the CHRYSO company for financing this project and the French company ARMINES for managing the contract. Thanks also to Jean-Claude Roux (IMT Mines Alès, France) for his help with the SEM analysis and Kevin Roque (IMT Mines Alès, France) for the particles size analysis of the cement pastes.

\section{REFERENCES}

1. Berodier, M. J. "[Ph.D Thesis], Impact of the Supplementary Cementitious Materials on the kinetics and microstructural development of cement hydration." Ecole Polytechnique Fédérale de Lausanne, 2015.

2. Kocaba, V. "[PhD. Thesis] Development and Evaluation of Methods to Follow Microstructural Development of Cementitious Systems Including Slags," 2009.

3. Ramachandran, V. S. "Action of triethanolamine on the hydration of tricalcium aluminate," Cement and Concrete Research, V. 3, No. 1, 1973, pp. 41-54.

4. Yang, S., Wang, J., Cui, S., et al. "Impact of four kinds of alkanolamines on hydration of steel slag-blended cementitious materials," Construction and Building Materials, V. 131, 2017, pp. 655-66.

5. Yaphary, Y. L., Yu, Z., Lam, R. H. W., et al. "Effect of triethanolamine on cement hydration toward initial setting time," Construction and Building Materials, V. 141, 2017, pp. 94-103.

6. Xu, Z., Li, W., Sun, J., et al. "Research on cement hydration and hardening with different alkanolamines," Construction and Building Materials, V. 141, 2017, pp. 296-306.

7. Jachiet, M., Azéma, N., Le Saoût, G., et al. "Influence of triethanolamine on cement pastes at early age of hydration," Advances in Cement Research, V. 30, No. 4, 2018, pp. $159-71$.

8. Jachiet, M. "[Ph.D Thesis], Etude des principaux modes d'action de systèmes accélérateurs des ciments Portland." Université de Montpellier, 2017.

9. Autier, C. “[Ph.D Thesis], Etude de l'adjuvantation de pâtes cimentaires par différents polycarboxylates: la mésostructure: un lien entre interactions organo-minérales et propriétés macroscopiques." Université Montpellier II, 2013.

10. Quemada, D., and Berli, C. "Energy of interaction in colloids and its implications in rheological modeling," Advances in Colloid and Interface Science, V. 98, No. 1, 2002, pp. 51-85.

11. Taylor, H. F. W. “Cement chemistry,” 2nd editio, Thomas Telford, 1997.

12. Mitchell, B. S. "An Introduction to Materials Engineering and Science: For Chemical and Materials Engineers," v. vol. 3, 4th edition, 2004, 900-902 pp.

13. Shannon, R. D., Shannon, R. C., Medenbach, O., et al. "Refractive Index and Dispersion 
of Fluorides and Oxides," Journal of Physical and Chemical Reference Data, V. 31, No. 4, 2002, pp. 931-70.

14. Schumann, W. "Gemstones of the wolrd," Sterling Publishing Co., 2009, 323 pp.

15. Wilson, M. J. "Sheet Silicates : Clay Minerals.” Rock-forming Minerals. 2nd ed. The Geological Society, 2013.

16. Cyr, M. "[Ph.D Thesis], Contribution à la caractérisation des fines minérales et à la compréhension de leur rôle joué dans le comportement rhéologique des matrices cimentaires." 1999.

17. Arvaniti, E. C., Juenger, M. C. G., Bernal, S. A., et al. "Determination of particle size, surface area, and shape of supplementary cementitious materials by different techniques," Materials and Structures, V. 48, No. 11, 2015, pp. 3687-701.

18. Yan-Rong, Z., Xiang-Ming, K., Zi-Chen, L., et al. "Influence of triethanolamine on the hydration product of portlandite in cement paste and the mechanism," Cement and Concrete Research, V. 87, 2016, pp. 64-76.

19. Lothenbach, B., and Winnefeld, F. "Thermodynamic modelling of the hydration of Portland cement," Cement and Concrete Research, V. 36, No. 2, 2006, pp. 209-26.

20. Mengual, O., Meunier, G., Cayre, I., et al. "Characterisation of instability of concentrated dispersions by a new optical analyser: the TURBISCAN MA 1000," Colloids and Surfaces A: Physicochemical and Engineering Aspects, V. 152, Nos. 1-2, 1999, pp. 111-23.

21. Lothenbach, B., Le Saout, G., Gallucci, E., et al. "Influence of limestone on the hydration of Portland cements," Cement and Concrete Research, V. 38, No. 6, 2008, pp. 848-60.

22. Demeyer, J.-F. “[Ph.D Thesis], Caractérisation de l'homogénéité de mélange de poudres et de l'agitation en mélangeur triaxe." 2007.

23. Boustingorry, $\mathrm{P}$. “[PhD. Thesis] Elaboration d'un matériau composite à matrice gypse et renfort bois fragmenté - Amélioration de la résistance au vissage de produits préfabriqués en gypse.” Ecole Nationale Supérieure des Mines de Saint-Etienne, 2002.

24. Scrivener, K. L., and Nonat, A. "Hydration of cementitious materials, present and future," Cement and Concrete Research, V. 41, No. 7, 2011, pp. 651-65.

25. Juilland, P., Gallucci, E., Flatt, R., et al. "Dissolution theory applied to the induction period in alite hydration," Cement and Concrete Research, V. 40, No. 6, 2010, pp. 83144.

26. Kocaba, V., Gallucci, E., and Scrivener, K. L. "Methods for determination of degree of reaction of slag in blended cement pastes," Cement and Concrete Research, V. Special Vo, 2012. 
Table 1-Chemical and mineralogical characteristics of the used materials with in paren theses, the standard deviation performed on at least three experiments. The column "Difference" presents the deviation obtain for two measurements on the same material.

\begin{tabular}{|c|c|c|c|c|c|c|c|c|c|c|c|c|}
\hline \multirow{3}{*}{$\mathrm{SiO}_{2}$} & \multicolumn{4}{|c|}{ XRF-analysis [wt.\%] } & \multicolumn{8}{|c|}{ Mineralogical phase composition [wt.\%], Rietveld analysis } \\
\hline & \multirow{2}{*}{$\begin{array}{r}\text { Clinker } \\
19.8\end{array}$} & \multirow{2}{*}{$\begin{array}{c}\begin{array}{c}\text { Calcium } \\
\text { sulfate }\end{array} \\
5.14\end{array}$} & \multirow{2}{*}{$\begin{array}{l}\text { Slag } \\
33.3\end{array}$} & \multirow{2}{*}{$\begin{array}{c}\text { Difference } \\
0.3\end{array}$} & \multicolumn{2}{|c|}{ Clinker } & \multicolumn{2}{|c|}{ Calcium sulfate } & \multicolumn{2}{|l|}{ Slag } & \multicolumn{2}{|c|}{ Limestone } \\
\hline & & & & & $\mathrm{C}_{3} \mathrm{~S}$ & $\begin{array}{l}69.1 \\
(1.7)\end{array}$ & Gypsum & $\begin{array}{l}21.2 \\
(4.7)\end{array}$ & Merwinite & 0.6 & Calcite & $\begin{array}{l}99.2 \\
(0.6)\end{array}$ \\
\hline $\mathrm{Al}_{2} \mathbf{O}_{3}$ & 5.22 & 1.47 & 12.1 & 0.1 & $\mathrm{C}_{2} \mathrm{~S}$ & $\begin{array}{r}7.8 \\
(1.8)\end{array}$ & Anhydrite & $\begin{array}{c}65.6 \\
(7.2)\end{array}$ & Calcite & 0.8 & Quartz & $\begin{array}{r}0.8 \\
(0.6)\end{array}$ \\
\hline $\mathrm{Fe}_{2} \mathrm{O}_{3}$ & 2.66 & 0.53 & 0.27 & 0.2 & $\mathrm{C}_{4} \mathrm{AF}$ & $\begin{array}{r}11.0 \\
(0.5)\end{array}$ & Quartz & $\begin{array}{r}3.4 \\
(0.4)\end{array}$ & Amorphous & 98.6 & & \\
\hline $\mathrm{TiO}_{2}$ & 0.15 & $<0.01$ & 0.59 & 0.01 & $\mathbf{C}_{3} \mathbf{A}$ & $\begin{array}{r}6.1 \\
(0.6)\end{array}$ & Dolomite & $\begin{array}{r}6,0 \\
(2.4)\end{array}$ & & & & \\
\hline $\mathbf{K}_{2} \mathbf{O}$ & 0.91 & 0.39 & 0.43 & 0.02 & Periclase & $\begin{array}{r}4.1 \\
(0.1)\end{array}$ & Illite & $\begin{array}{r}4,0 \\
(2.1)\end{array}$ & & & & \\
\hline $\mathrm{Na}_{2} \mathrm{O}$ & 0.34 & 0.14 & 0.23 & 0.01 & Lime & $\begin{array}{r}1.3 \\
(0.4)\end{array}$ & & & & & & \\
\hline $\mathrm{CaO}$ & 64.2 & 36.6 & 41.0 & 0.2 & Aphtitalite & $\begin{array}{r}0.5 \\
(0.4)\end{array}$ & & & & & & \\
\hline MgO & 4.93 & 1.82 & 7.62 & 0.2 & & & & & & & & \\
\hline $\mathrm{SO}_{3}$ & 0.85 & 48.0 & 2.97 & 0.1 & & & & & & & & \\
\hline MnO & 0.05 & $<0.01$ & 0.18 & 0.01 & & & & & & & & \\
\hline $\mathbf{P}_{2} \mathbf{O}_{5}$ & 0.11 & 0.02 & 0.06 & 0.01 & & & & & & & & \\
\hline $\begin{array}{l}\text { LOI } \\
\left(1025^{\circ} \mathrm{C}\right)\end{array}$ & 0.6 & 5.7 & 1 & - & & & & & & & & \\
\hline
\end{tabular}

Table 2-Refractive indexes calculated and used for cementitious materials

\begin{tabular}{lcc}
\hline Material & $\begin{array}{c}\text { Refractive index } \\
\text { n (real part) }\end{array}$ & $\begin{array}{c}\text { k (imaginary } \\
\text { part) }\end{array}$ \\
\hline Clinker & $1.75 \pm 0.09$ & 0.1 \\
Calcium sulfate & $1.58 \pm 0.27$ & 0.1 \\
Slag & $1.59 \pm 0.04$ & 0.1 \\
Limestone & $1.65 \pm 0.01$ & 0.1 \\
OPC & $1.74 \pm 0.1$ & 0.1 \\
OPC-S & $1.71 \pm 0.08$ & 0.1 \\
OPC-L & $1.70 \pm 0.06$ & 0.1
\end{tabular}

Table 3-Water to binder ratios after paste dilution for Turbiscan analysis for a constant volume fraction 


\begin{tabular}{lc}
\hline Cement system & W/B \\
\hline OPC & 1.78 \\
OPC-L & 1.89 \\
OPC-S & 1.86 \\
L & 2.06 \\
S & 1.98
\end{tabular}

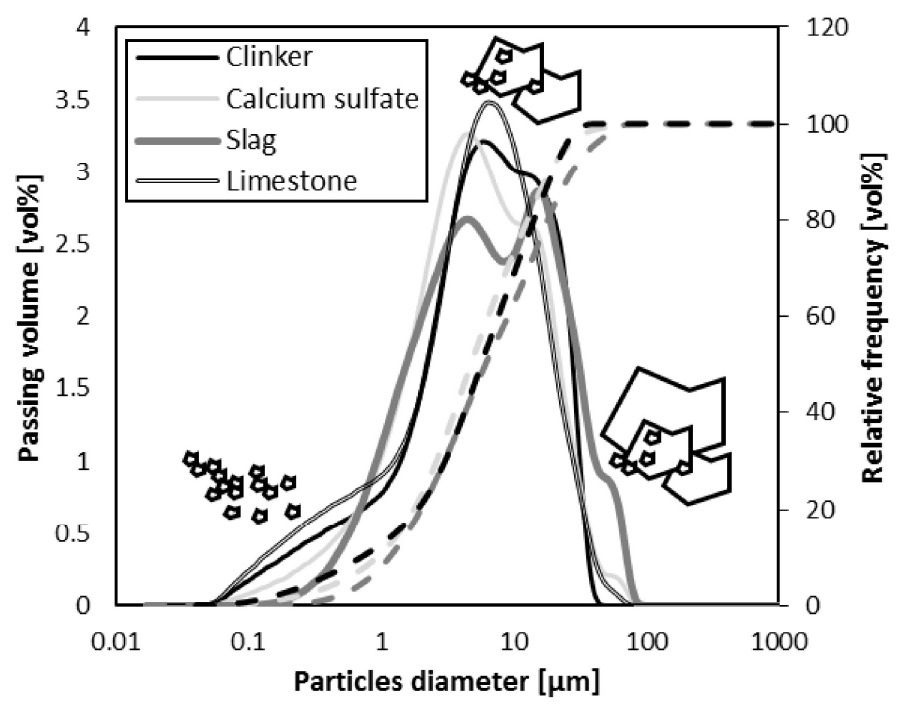

Figure 1-Particle size distributions of the blended materials measured by laser granulometry in isopropanol. The solid lines show differential distributions and the dashed lines show cumulative distributions.

Table 4-Granular and physical characteristics of the used materials

\begin{tabular}{|c|c|c|c|c|}
\hline \multicolumn{5}{|c|}{ Granular and physical characteristics } \\
\hline & Clinker & $\begin{array}{l}\text { Calcium } \\
\text { sulfate }\end{array}$ & Slag & Limestone \\
\hline BET (Brunauer-Emmett-Teller) specific surface $\left[\mathrm{m}^{2} / \mathbf{k g}\right]$ & $1403 \pm 14$ & $3645 \pm 21$ & $2041 \pm 12$ & $2679 \pm 42$ \\
\hline Blaine specific surface $\left[\mathrm{m}^{2} / \mathrm{kg}\right]$ & $471 \pm 5$ & $320 \pm 3$ & $494 \pm 3$ & $688 \pm 4$ \\
\hline Density & $3.20 \pm 0.01$ & $2.87 \pm 0.01$ & $2.86 \pm 0.02$ & $2.75 \pm 0.02$ \\
\hline Spreading (dmax-dmin) $[\mu \mathrm{m}]^{a}$ & $52.6 \pm 0.2$ & $101.1 \pm 0.1$ & $111 \pm 5.7$ & $92.1 \pm 0.1$ \\
\hline Main mode $[\mu \mathrm{m}]^{\text {a }}$ & $6.5 \pm 0.1$ & $4.9 \pm 0.1$ & $14.9 \pm 0.8$ & $7.1 \pm 0.1$ \\
\hline \multicolumn{5}{|c|}{$\left[1 \mathrm{~m}^{2} / \mathrm{kg}=703.1 \mathrm{in}^{2} / \mathrm{lb} ; 1 \mathrm{~g} / \mathrm{cm}^{3}=0.0361 \mathrm{lb} / \mathrm{in}^{3} ; 1 \mu \mathrm{m}=0.0394 \mathrm{mil}\right]$} \\
\hline
\end{tabular}



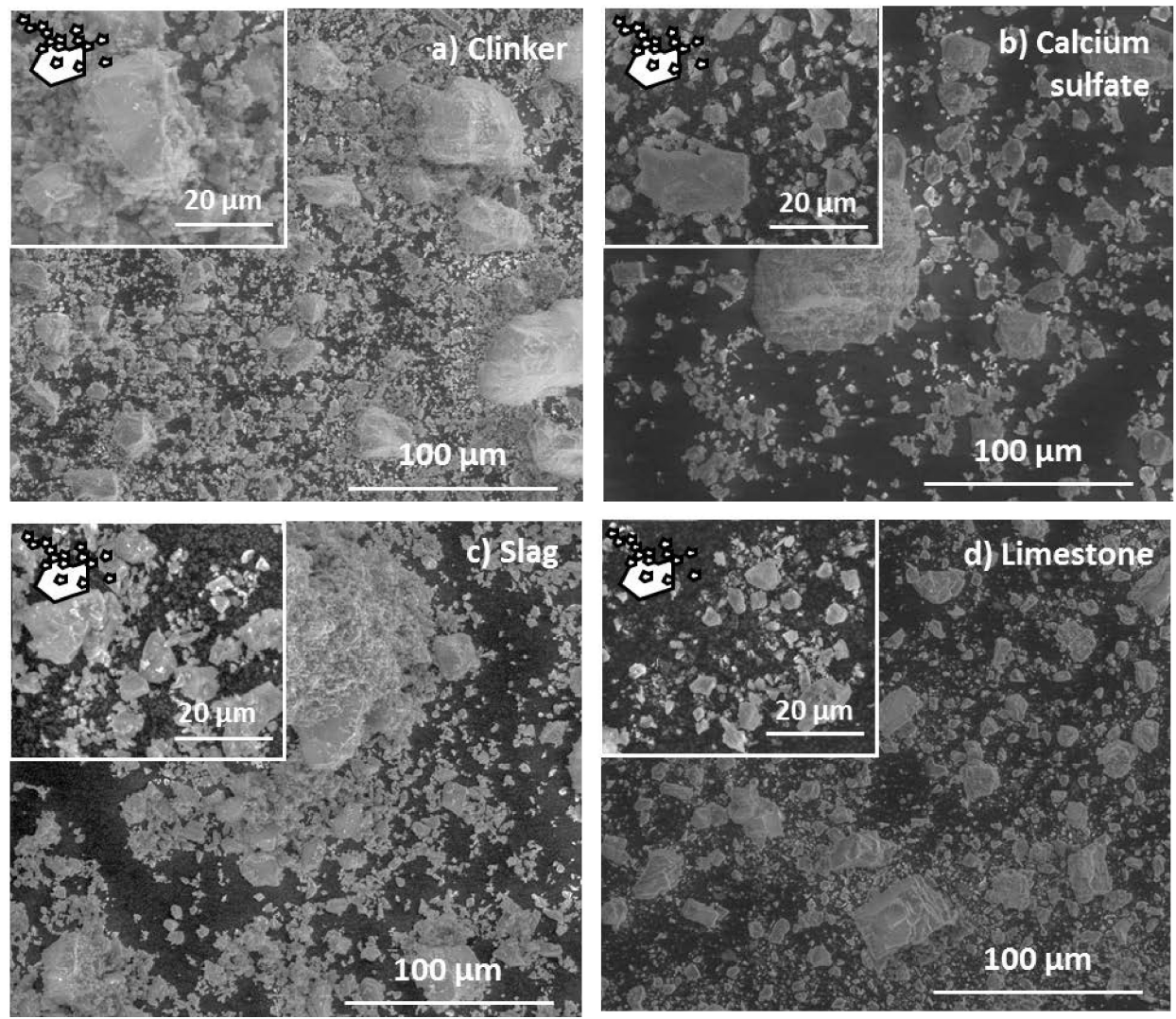

$[1 \mu \mathrm{m}=0.0394 \mathrm{mil}]$

Figure 2-SEM micrographs of powders of (a) clinker, (b) calcium sulfate, (c) slag and (d) limestone 


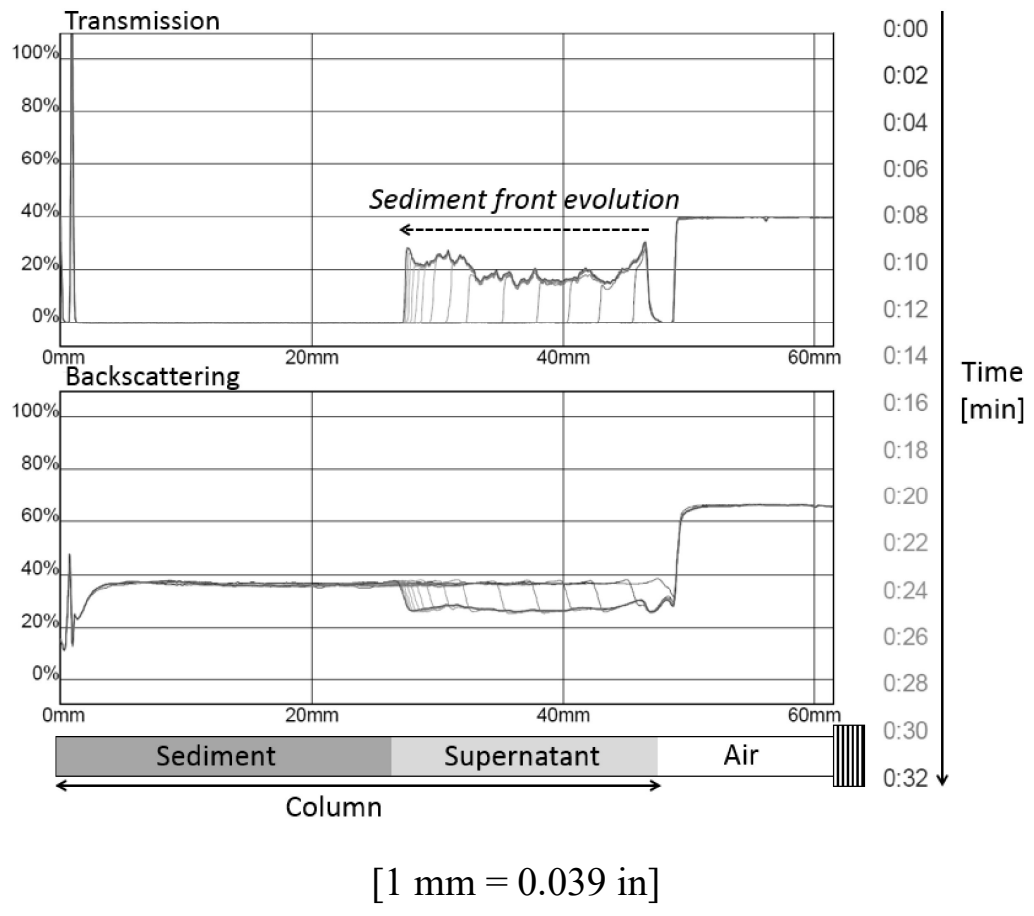

Figure 3-Transmitted and backscattering signals of the settling profile of OPC diluted paste

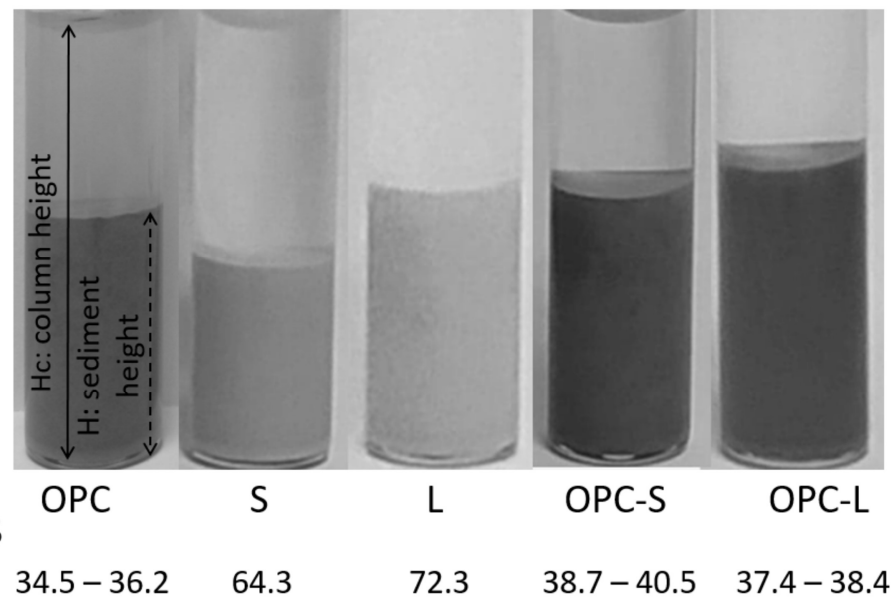

signal of $34.5-36.2 \quad 64.3 \quad 72.3 \quad 38.7-40.5 \quad 37.4-38.4$

Figure 4-Visual appearance of settling columns for OPC, OPC-S, OPC-L, slag and limestone at $\mathbf{3 5}$ minutes of hydration 


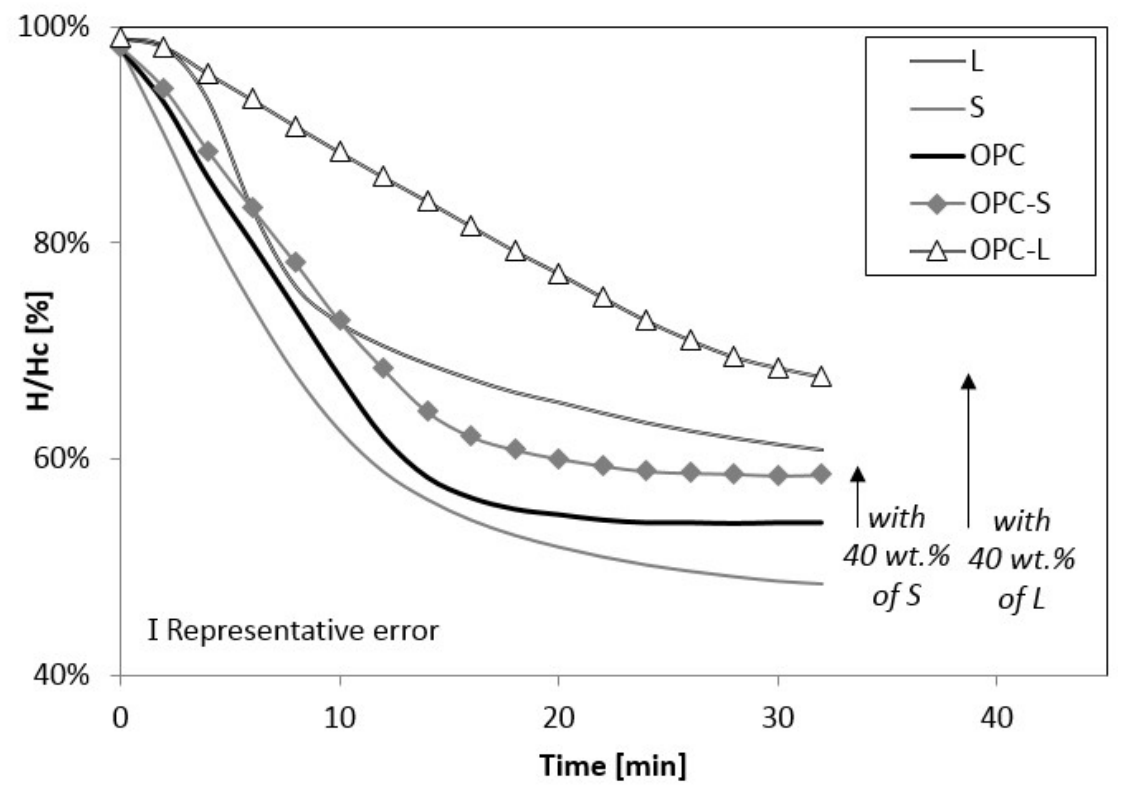

Figure 5-Evolution of sediment height through time for diluted pastes of limestone (L), slag (S), OPC, OPC-S and OPC-L

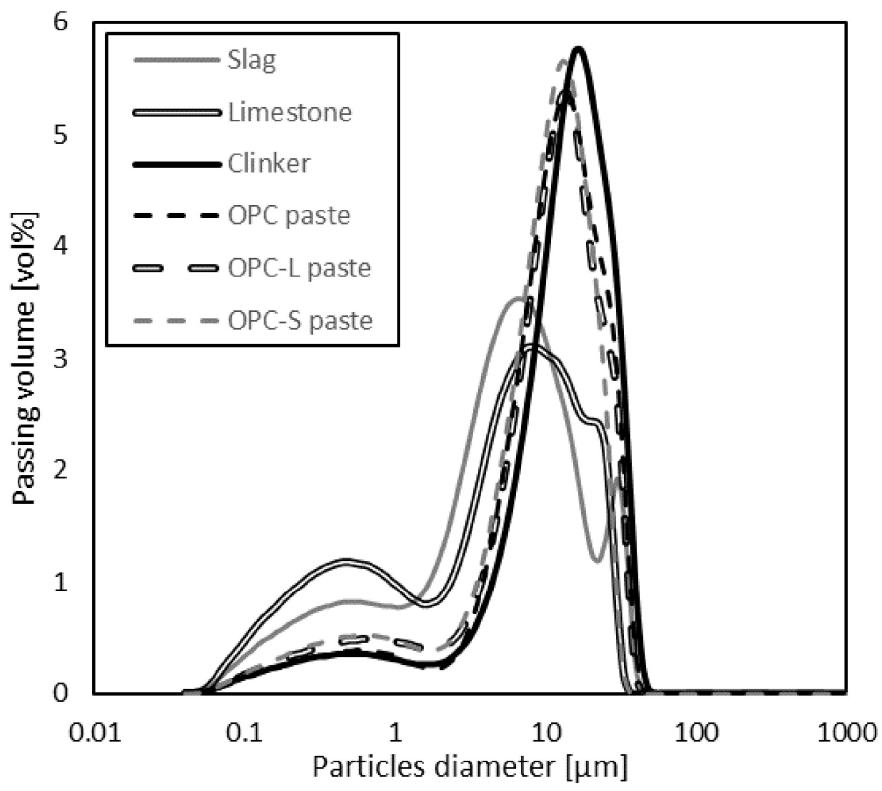

$[1 \mu \mathrm{m}=0.0394 \mathrm{mil}]$

Figure 6-Particle size distributions of the raw powders (slag, limestone and clinker) and cement pastes (OPC, OPC-S and OPC-L) measured in synthetic interstitial liquid at 10 minutes of hydration 

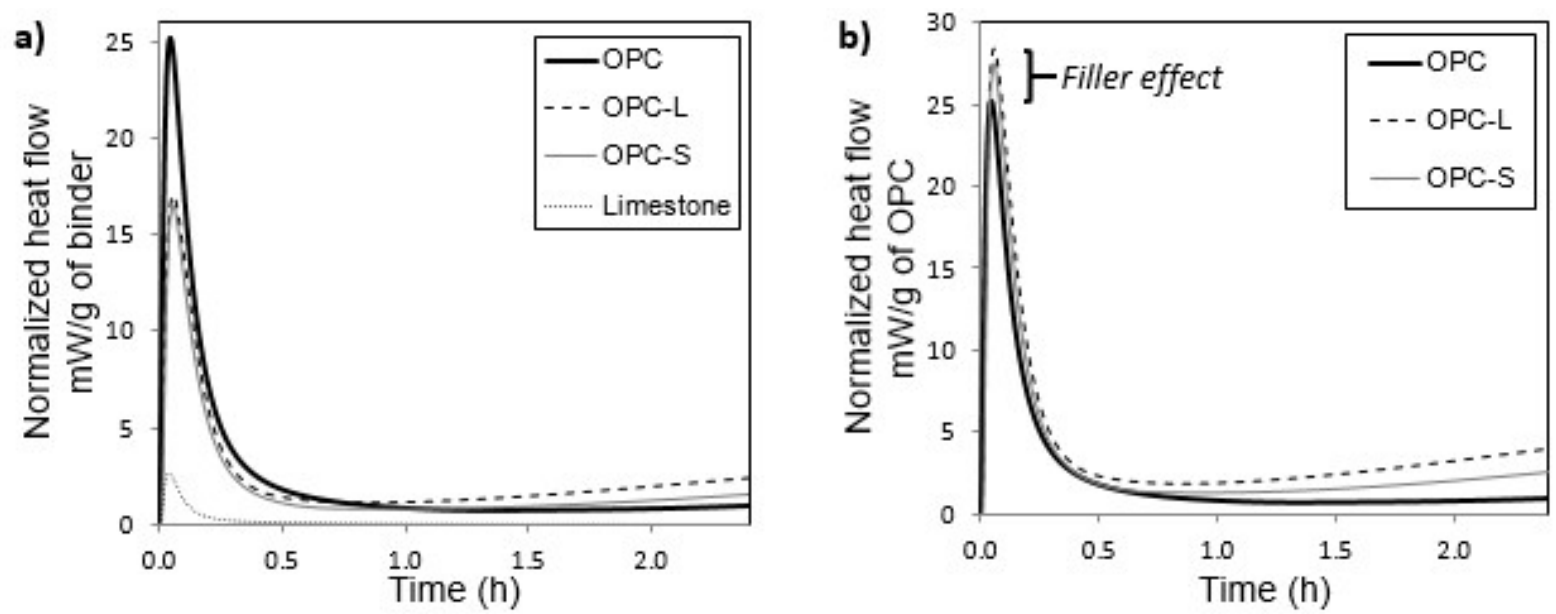

$$
[1 \mathrm{~mW} / \mathrm{g}=0.0006 \mathrm{hp} / \mathrm{lb}]
$$

Figure 7-Normalized heat flow by weight of binder (a) and of OPC (b) at early age

a)

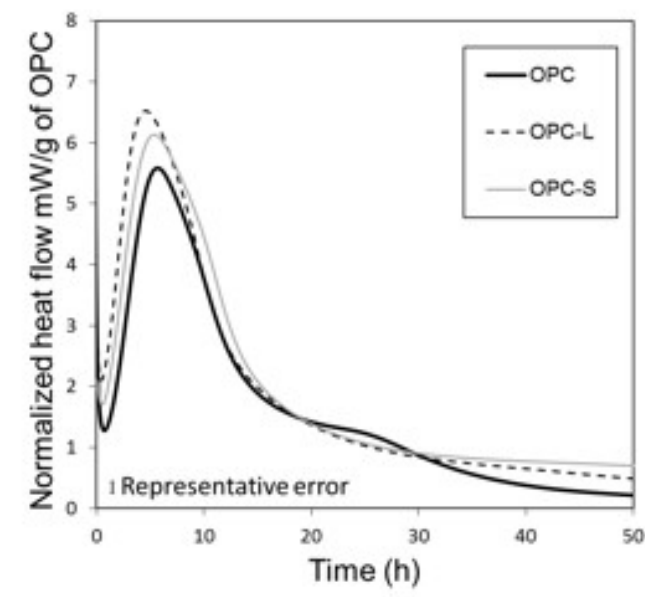

b)

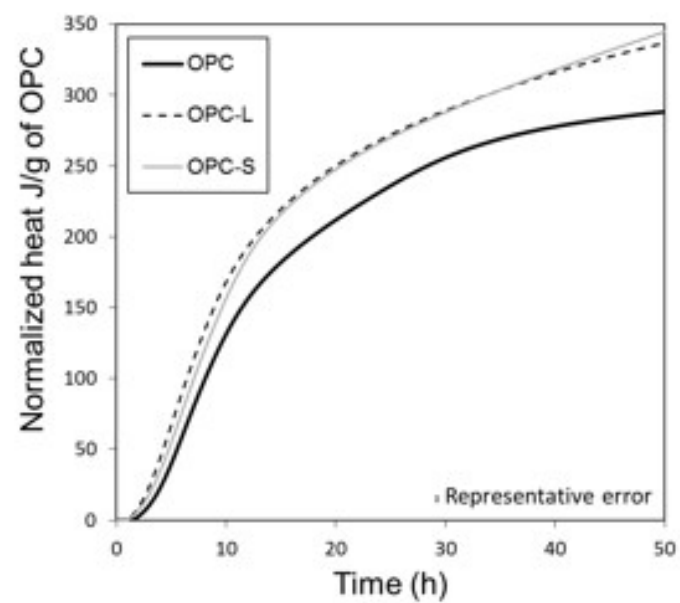

[1 mW/g = $0.0006 \mathrm{hp} / \mathrm{lb} ; 1 \mathrm{~J} / \mathrm{g}=108 \mathrm{cal} / \mathrm{lb}]$

Figure 8-Heat flow (a) and cumulative heat (b) of OPC and blended cement pastes 

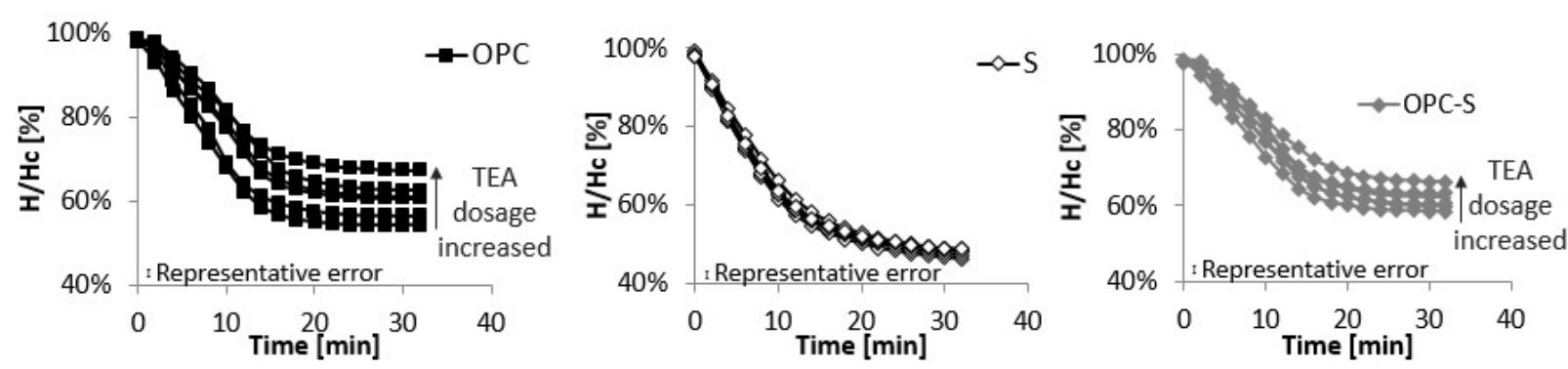

Figure 9-Evolution of the sediment front as a function of time with different TEA dosages on OPC, OPC-S and S systems

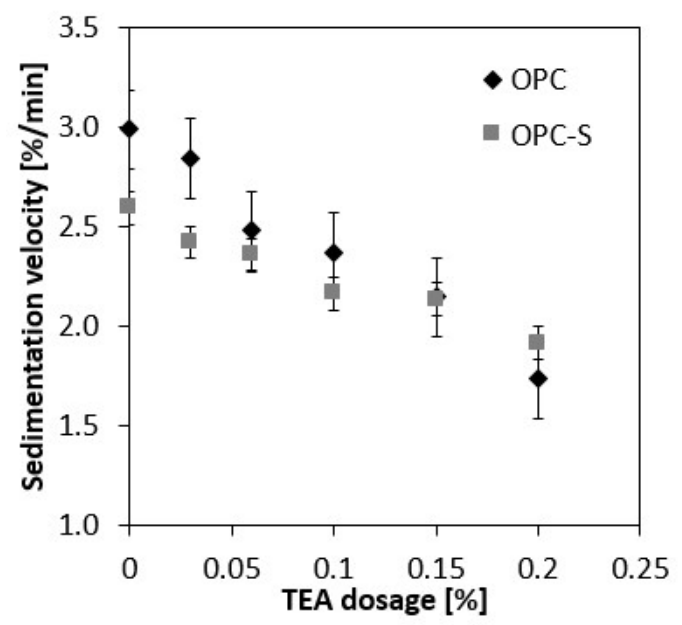

Figure 10-Settling velocity of OPC and OPC-S diluted pastes with different TEA dosages (wt.\%) 
a)

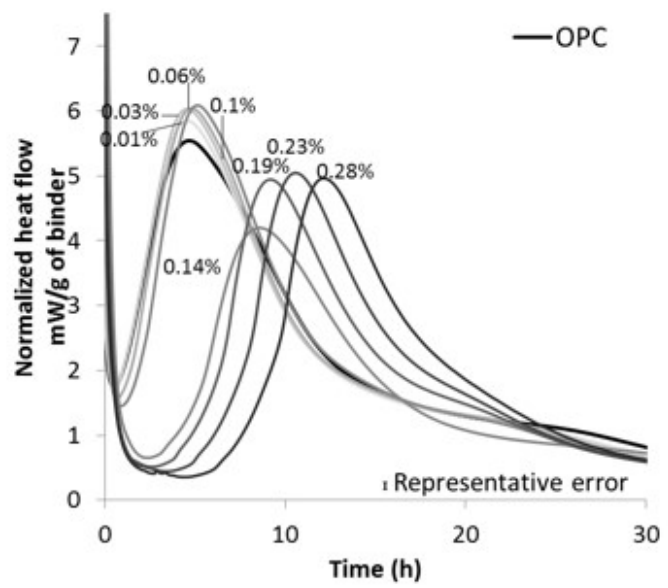

c)

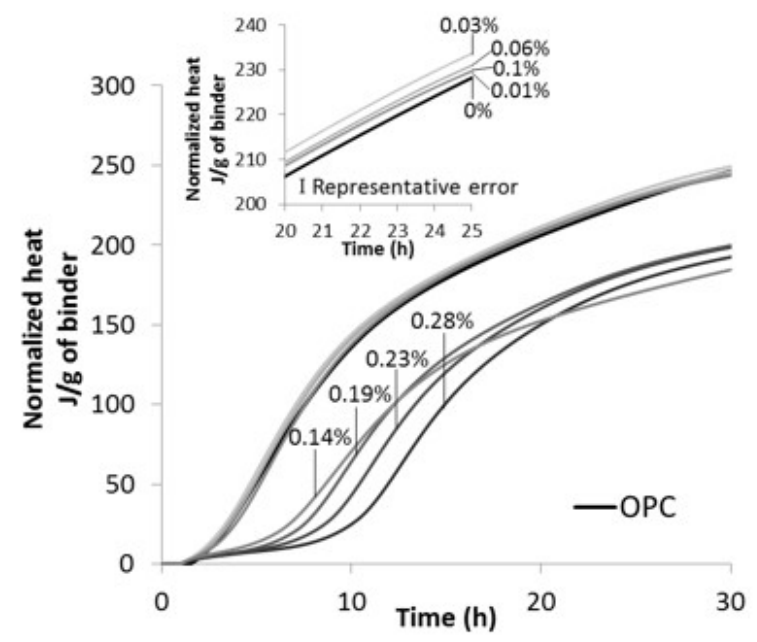

b)

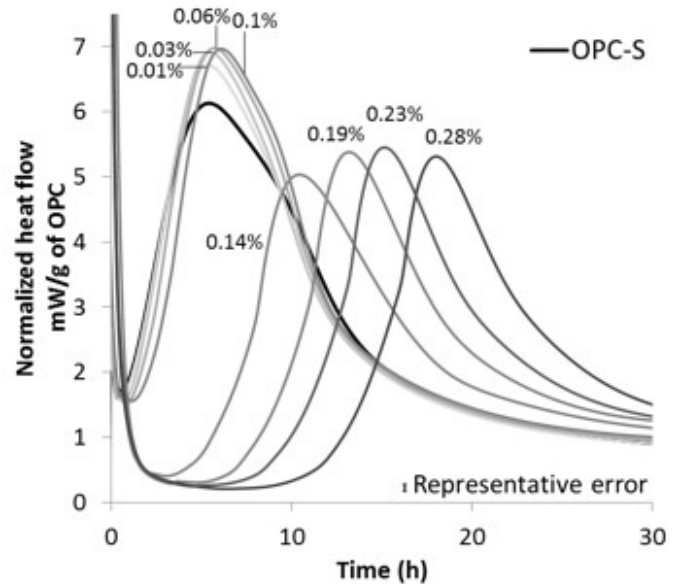

d)

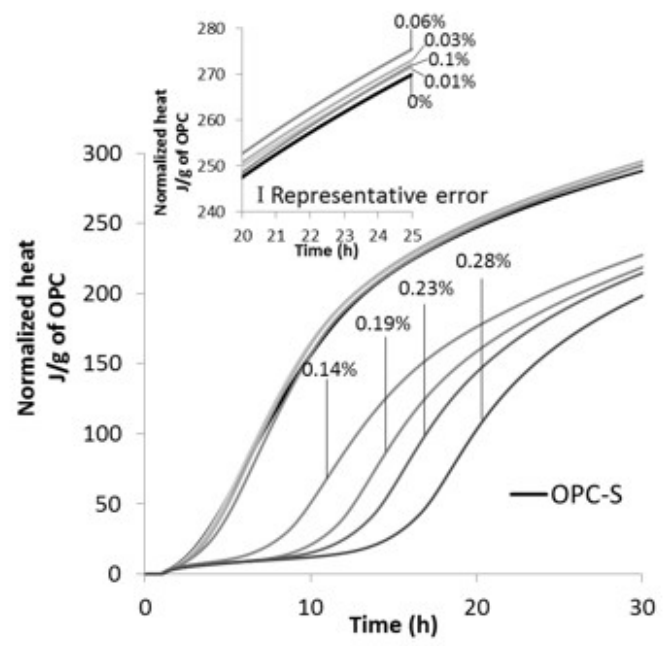

$[1 \mathrm{~mW} / \mathrm{g}=0.0006 \mathrm{hp} / \mathrm{lb} ; 1 \mathrm{~J} / \mathrm{g}=108 \mathrm{cal} / \mathrm{lb}]$

Figure 11-Specific heat flow of a) OPC and b) OPC-S and cumulative heat of c) OPC and d) OPC-S normalized to the mass of OPC at different dosages of TEA 